\title{
THE DEVELOPMENT OF SLOW-RELEASED FUNGICIDE PREPARATIONS BASED ON BIODEGRADABLE POLY(3-HYDROXYBUTYRATE) TO SUPPRESS ROOT-ROT PATHOGENIC FUNGI
}

\author{
Prof. Svetlana Prudnikova ${ }^{1}$, \\ MSc Nadezhda Streltsova ${ }^{1}$, \\ Prof. Tatiana Volova ${ }^{1,2}$ \\ ${ }^{1}$ Siberian Federal University, Russia \\ ${ }^{2}$ Institute of Biophysics SB RAS, Russia
}

\begin{abstract}
The use of chemical crop protection products takes the lead in worldwide agricultural technologies. However, a significant part of pesticides does not achieve the goals, disperses in the environment, and accumulates in crops and food products. Targeted and controlled delivery of pesticides helps to decrease the overuse of chemicals due to the prolonged gradual release of active ingredients from matrices and maintaining of effective concentration in the application zone. The aim of this study was to evaluate the effectiveness of embedded fungicide formulations to protect crops from root-rot pathogens. Three fungicides (tebuconazole, epoxiconazole, and azoxystrobin) were embedded in biodegradable base made from a mixture of poly(3-hydroxybutyrate) and one of the fillers - peat, clay or wood flour. The powdered components, polymer + filler + fungicide (50:30:20 wt.\%), were mixed and prepared as granules. The fungicidal effect of experimental formulations on root-rot pathogens was studied in vitro and in the rhizosphere soil of test crops (spring wheat and barley) in comparison with effect of conventional methods of soil treatment with fungicides. Regardless of the filler and the type of preparation, all formulations had a pronounced inhibitory effect on the growth of Fusarium verticillioides colonies. In the field soil samples with embedded fungicides, a decrease in the number of micromycetes, in particular phytopathogenic fungi Alternaria and Fusarium, was shown. The traditional forms of fungicides affected development of saprotrophic fungi, reduced the abundance of bacteria, and shifted the ratio of dominant taxa. In contrast, no decrease in the number of bacteria in soil samples was detected when embedded fungicides was used, and besides a stimulating effect on microbial abundance was revealed. In long-term experiments with plants, the healing effect of embedded formulations on the wheat and barley roots was obtained. After tillering stage, the biological effectiveness of both embedded and free fungicides was comparable. After heading stage, the maximum biological effectiveness of embedded fungicides, reached about $90 \%$ and superior the efficacy of free fungicides, was detected. Thus, developed embedded fungicides demonstrated a long-term functioning in the soil and effective suppression of phytopathogenic fungi on the wheat and barley roots.
\end{abstract}

Keywords: fungicides, poly(3-hydroxybutyrate), slow-released pesticides, soil microflora, crops 


\section{INTRODUCTION}

Phytopathogenic fungi reduce the productivity of crops, impair the quality of seeds and result in a loss of up to $10 \%$ of the yield, causing great damage to agriculture. Among the phytopathogens, a complex of Fusarium fungi, which are widely specialized and affecting various types of plants, causing root rots, tracheomycosis, wilt, head blight of wheat, and grain spoilage, takes one of the leading places. Besides, some Fusarium species produce mycotoxins cause food intoxication hazardous to human health $[1,2]$.

The use of fungicides in agriculture reduce the number of plant pathogens in soil and crop losses. However, wide-scale soil treatment and seed dressing contribute to the accumulation of chemicals in soil and groundwater, as well as the spread of resistance to the chemicals among phytopathogenic fungi [3]. In addition, studies by several authors have shown that triazole fungicides have a phytotoxic effect on crop plants [4].

Due to the low specificity of the action, fungicides applied to the soil inhibit the growth of both harmful and saprotrophic microorganisms, adversely affecting the soil microbial community as a whole. Direct effect of pesticides on soil microbiome is determined by chemical properties and delivery method of the pesticide [5, 6]. Recently, the development of novel forms of pesticides embedded in a biodegradable base has become an urgent area in agrochemical research $[4,7,8]$.

Microbial polymers, polyhydroxyalkanoates, fit the criteria such as biodegradability, non-toxicity, and compatibility with agrochemicals that are needed to construct controlled-release formulations of agrichemicals [9-10]. The release rate of the active substance from the polymer base into the soil is determined by the susceptibility of polymer to microbial biodegradation, and can vary by introducing fillers into the base. As fillers, available natural materials are usually used (sawdust, clay, peat, biochar, etc.), which not only provide an opportunity to control the release rate of agrochemicals, but also reduce the inhibitory effect of pesticides on the enzymatic activity of the soil and stimulate the development of soil microbiota $[11,12]$.

Soil microorganisms make a major contribution to detoxification and transformation of pesticides and bioremediation of the environment. Therefore, important indicators are the abundance and taxonomic composition of soil microorganisms, as they affect the degradation rate of the composite base, the transformation of pesticides in the soil, and determine soil fertility and plant health [13].

This study was aimed to investigation of the effects of embedded and free fungicides on the growth of Fusarium colonies in vitro, structure of microbial community of wheat and barley rhizosphere and infection of plants by root rot pathogens.

\section{MATERIALS AND METHODS}

Fungicide embedding technique. Systemic fungicides from the classes of triazoles (tebuconazole and epoxyconazole) and strobilurins (azoxystrobin) were used to make fungicidal preparations embedded into a mixed base containing biopolymer poly(3hydroxybutyrate) $[\mathrm{P}(3 \mathrm{HB})]$ and one of the fillers - wood flour, peat, or clay. A homogeneous mixture of the components, included $50 \mathrm{wt} . \%$ of $\mathrm{P}(3 \mathrm{HB}), 30 \mathrm{wt} . \%$ of filler and $20 \mathrm{wt} . \%$ of the fungicide, was placed in a granulator (Fimar, Italy) and granules $2-4 \mathrm{~mm}$ in size were made. 
The study of the fungicidal activity of experimental formulations in vitro. The fungicidal effect of embedded formulations on the growth of the phytopathogenic fungus Fusarium verticillioides (Sacc.) Nirenberg (1976) was studied by the diffusion method on an agar medium with malt extract (MEA, Sigma-Aldrich, USA). The fungal culture was plated in a Petri dish with sterile MEA, and granules contained one of the fungicide were placed on the opposite side. The diameter of the fungal colony was measured after 7 days of incubation at $25{ }^{\circ} \mathrm{C}$ and the growth inhibition was evaluated in comparison with the positive control (free active ingredient of the fungicide) and the negative control (the fungal mycelium grown without the fungicide).

The study of the fungicidal activity of experimental formulations on test plants in climate chambers. Test plants of wheat and barley were grown in containers with field soil in the photoperiodic mode using climatic chambers (Fitotron-LIA-2, Russia). The temperature varied from 10 to $22^{\circ} \mathrm{C}$, the illumination was $0-300 \mu \mathrm{mol} / \mathrm{m}^{2} / \mathrm{s}$, and the soil moisture was maintained at $50 \%$. At the same time as seeding, granules containing tebuconazole or epoxyconazole were placed into the soil. The dosage of fungicide introduced into the soil was varied by applying different amounts of granules. As a positive control, unembedded free pesticides dissolved in water were applied to the soil in accordance with the consumption rate: tebuconazole $2.7 \mathrm{mg} / \mathrm{m}^{2}$ and epoxiconazole $8.7 \mathrm{mg} / \mathrm{m}^{2}$. In variations with a negative control, fungicidal preparations were not used. To compare the effectiveness of the embedded and free fungicides, the number of plants infected with root rot pathogens was determined. Infection rate of the wheat and barley roots with a complex of phytopathogenic fungi Fusarium, Alternaria, and Bipolaris was studied by the wet chambers method (Russian Federal Standard 12044-93) in the following phases of plant development: germination, tillering, booting, heading, and early grain maturation.

Microbiological studies. The effect of the experimental formulations on the soil microbial community was studied by conventional microbiological methods. The abundance and taxonomic composition of the rhizosphere microflora of wheat and barley roots were analyzed by plating of soil suspension on nutrient agar for bacteria and on potato-dextrose agar for fungi. Pure cultures of micromycetes were isolated from samples of rhizosphere soil and identified by cultural and morphological features.

\section{RESULTS AND DISCUSSION}

Among the phytopathogens of the genus Fusarium, the species $F$. verticillioides has important agricultural and medical significance, since it not only affects the quality of grain, but also is capable of mycotoxins producing [1,2]. In an in vitro experiment, all embedded fungicides inhibited the growth of $F$. verticillioides colonies on a nutrient medium. Despite the insignificant contact area of the granules with the nutrient medium, the diffusion of the active substance facilitated to suppress the growth of mycelium. The diameter of fungal colonies in Petri dishes with fungicides was on average 2 times smaller than in the negative control without any fungicidal preparations (Fig. 1a). The average diameter of the fungal colonies on plates with experimental formulations was comparable to the diameter on plates with pure active ingredients. Azoxystrobin showed a slightly stronger fungicidal effect, however, no significant differences between the different types of fungicides were found. The use of different fillers did not affect the efficiency of the fungal colonies growth inhibition (Fig. 1b). Similar results were 
obtained in our previous studies of the tebuconazole formulations embedded in $\mathrm{P}(3 \mathrm{HB})$ matrix and shaped as films and pellets [12].
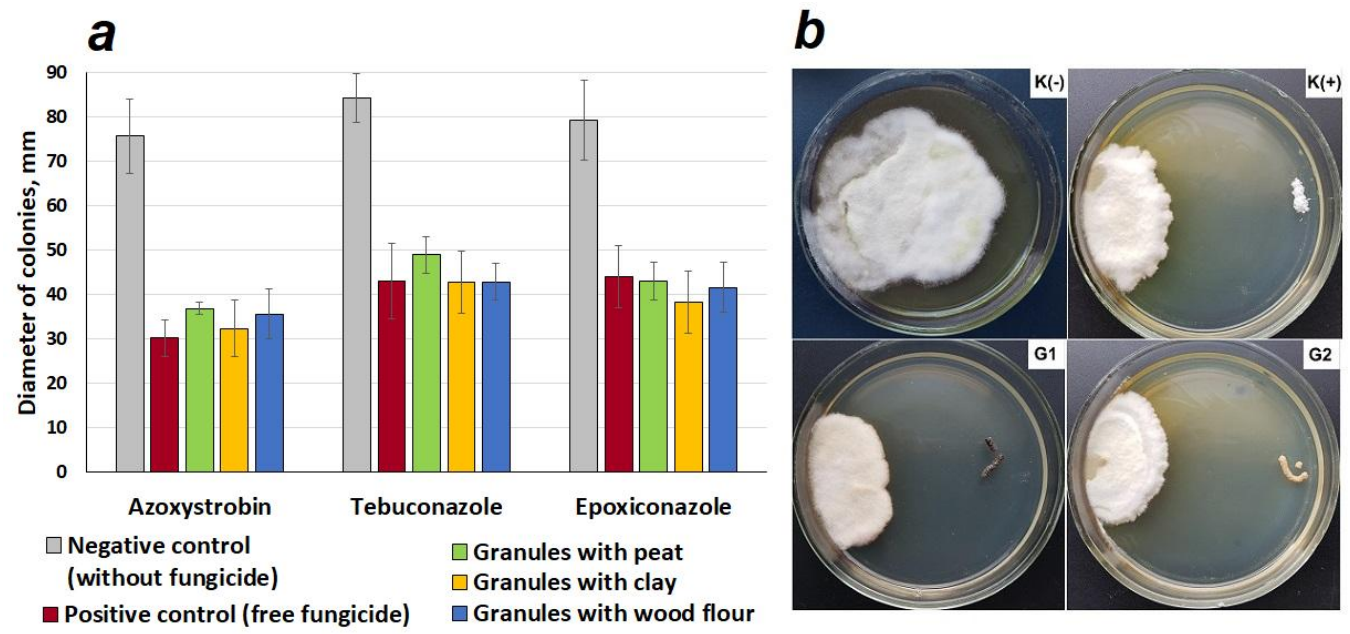

Fig. 1. Inhibition of the growth of Fusarium verticillioides by fungicidal preparations; $a$ - diameter of colonies; $b$ - photographs of fungus colonies on Petri dishes: $\mathrm{K}(-)-$ negative control, $\mathrm{K}(+)$ - positive control, G1 - granules of $\mathrm{P}(3 \mathrm{HB}) /$ peat/epoxyconazole, $\mathrm{G} 2$ - granules of $\mathrm{P}(3 \mathrm{HB}) /$ wood flour/epoxyconazole

For further study under controlled conditions of a long-term experiment, two fungicides (tebuconazole and epoxyconazole) and one type of filler (birch wood flour) were selected. A study of the root infection incidence on the barley and wheat plants was carried out in dynamics from germination stage to the early grain maturation. In the negative control, a high occurrence frequency of root rot pathogens (Fusarium, Alternaria, and Bipolaris) in test plants was detected. After 84 days of the experiment, the proportion of infected roots reached $47 \%$ in barley and $33.2 \%$ in wheat (Fig. 2). The traditional method of soil treatment with fungicides has shown high efficiency from the first days of the experiment; further, the proportion of infected roots remained at the same level.
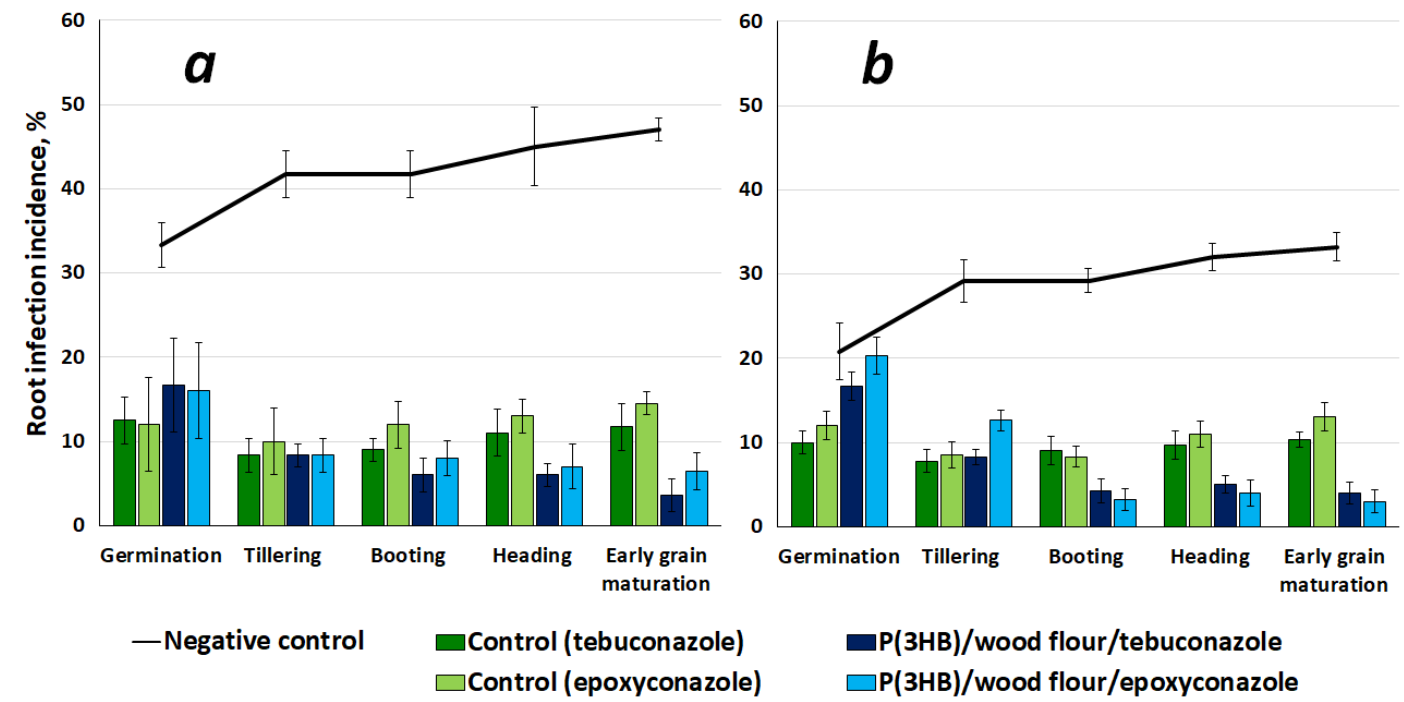

Fig. 2. The infection rates of barley $(a)$ and wheat $(b)$ roots at different stages of plant development 
At the germination stage, the action of embedded formulations was weaker than the action of free fungicides. This delay can be explained by the gradual release of the active substance from the polymer base and its accumulation in the soil. Nevertheless, at the next stages of plant development, the degree of the root infections incidence decreased and the effectiveness of deposited formulations was equal to free forms of fungicides, and even exceeding them 1.5-2 times.

Some authors show that the accumulation of fungicides in the soil leads to a decrease in the abundance and taxonomic diversity of soil microorganisms. First, this concerns the fungal community as a target for the action of fungicides [5, 6]. Microbiological analysis revealed a significant decrease in the number of micromycetes in the rhizosphere soil with embedded formulations as compared with untreated soil (Fig. 3). That kind of quantitative dynamics is consistent with a decrease in the infection of the plant root system with phytopathogenic fungi. Obviously, the fungicidal effect of the free forms of tebuconazole and epoxyconazole was weakened by the booting stage. This may be due to both leaching of the fungicides from the soil and enzymatic degradation by soil microorganisms.

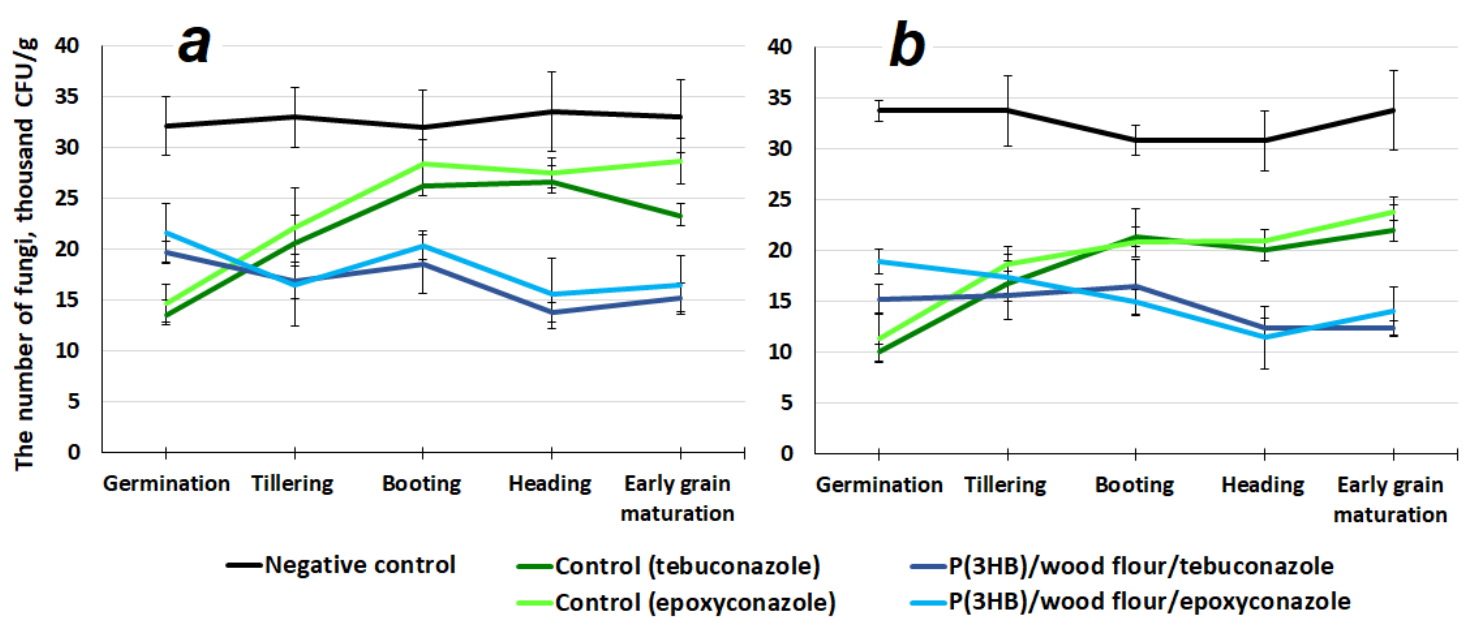

Fig. 3. The total number of micromycetes in the rhizosphere soil of barley (a) and wheat (b) with various fungicide delivery methods

The study of the taxonomic composition of soil micromycetes showed that the introduction of free and embedded fungicides led not only to a decrease in the abundance, but also to a shift in the proportions of the dominant fungi in the rhizosphere of plants. As it was revealed, the main decrease in the number of micromycetes occurred due to the suppression of phytopathogenic fungi, while the proportion of saprotrophs did not decrease. On day 84, fungi of the genus Trichoderma dominated in all soil samples, ranging from 50 to $77.5 \%$ in the barley rhizosphere and from 40 to $56 \%$ in wheat rhizosphere (Fig. 4). In second place was the genus Penicillium. Phytopathogenic fungi Fusarium and Alternaria were found in untreated soil at all stages of plant development, and by the end of the experiment, their sum reached $22 \%$ and $17 \%$ in the rhizosphere of barley and wheat, respectively. The introduction of free fungicides suppressed the development of the root infection on plants, but fungi of the genus Fusarium have been detected in the soil samples. Tebuconazole and 
epoxiconazole embedded in granules were the most effective in the inhibition of phytopathogens, since the fungi Fusarium and Alternaria were not detected in these samples throughout the experiment.

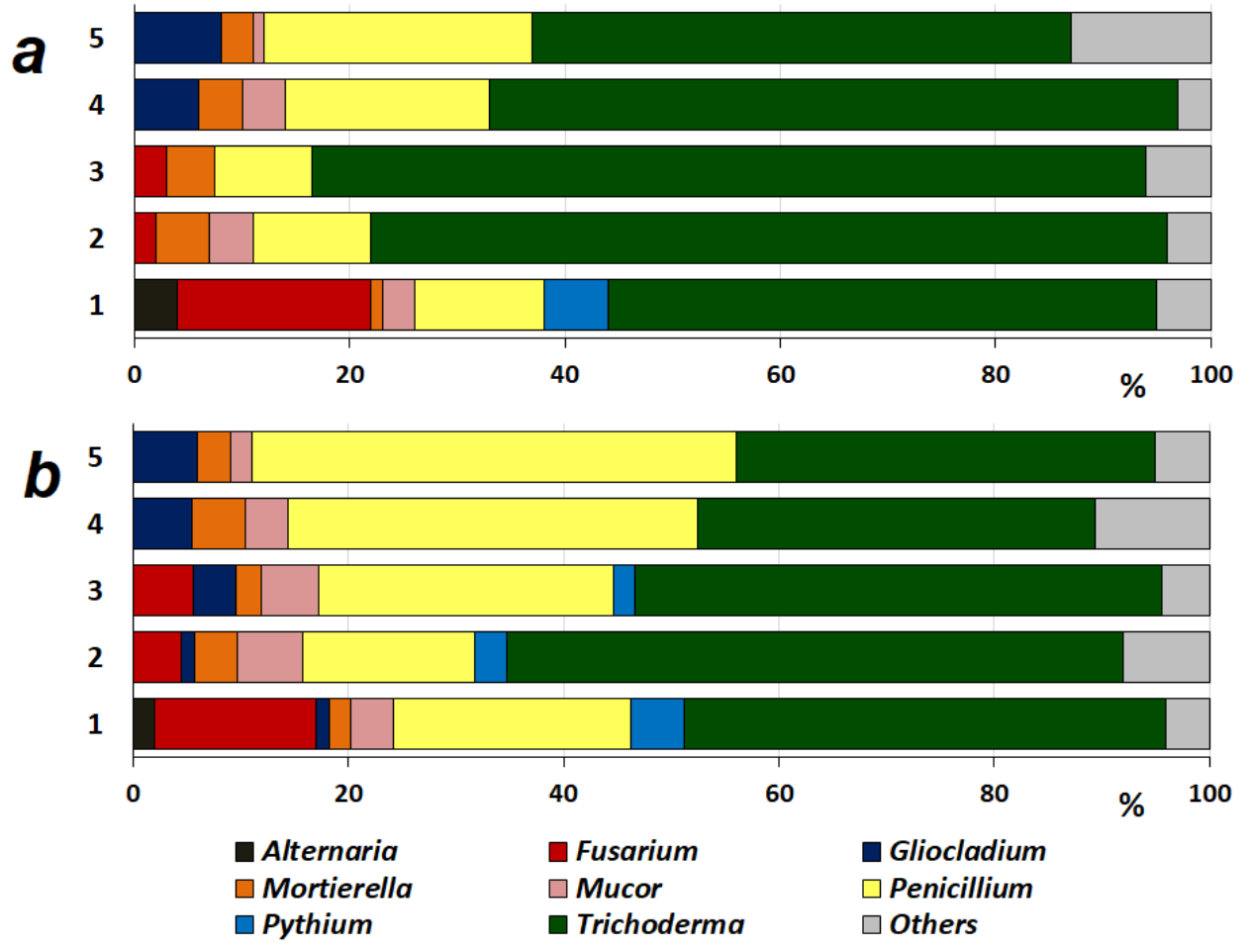

Fig. 4. The ratio of dominant genus of micromycetes in the rhizosphere soil of barley $(a)$ and wheat $(b)$ on day 84 of the experiment: 1 - negative control (without fungicide); 2 - positive control (free tebuconazole) 3 - positive control (free epoxiconazole); 4 $\mathrm{P}(3 \mathrm{HB}) /$ wood flour/tebuconazole; 5 - $\mathrm{P}(3 \mathrm{HB}) /$ wood flour/epoxiconazole

The effect of fungicides on soil microflora depends on a number of factors, including concentration, solubility, and resistance to degradation [5, 6]. An analysis of the bacterial community did not reveal significant fluctuations in the total number of bacteria in the rhizosphere of barley and wheat throughout the experiment. Since the achieved concentration of the active substance in the soil did not exceed the permissible values, inhibition of bacterial growth was not detected. This is consistent with the opinion of other authors that low concentrations of pesticides do not affect the number and activity of the bacterial community in the soil $[14,15]$.

\section{CONCLUSION}

The microbial polymer poly(3-hydroxybutyrate) mixed with natural fillers was used as the matrix for the embedding of systemic fungicides (azoxystrobin, tebuconazole and epoxyconazole) and production of granulated formulations. Regardless of the mixed base composition and the type of active ingredient, fungicide granules had a similar fungicidal effect in vitro. In a long-term experiment, slow-release formulations provided an effective suppression of phytopathogenic fungi development in the soil, equal or superior in effectiveness to the action of free fungicidal preparations. The absence of a negative impact of experimental formulations on saprotrophic soil microorganisms as 
well as the prolonged fungicidal effect on phytopathogenic fungi help to improve the root system of plants and increase the resistance to root rot pathogens. The proposed approach allows the use of biodegradable natural materials for designing long term and controlled-release formulation in order to reduce the environmental risks of environmental pesticide pollution.

\section{ACKNOWLEDGEMENTS}

This study was supported by the Ministry of Education and Science RF, Project "Agropreparations of the new generation: a strategy of construction and realization" (Agreement No 074-02-2018-328).

\section{REFERENCES}

[1] Binder E. M., Tan L. M., Chin L. M., Handl J., Richard J. Worldwide occurrence of mycotoxins in commodities, feeds and feed ingredients. Animal Feed Science and Technology. vol. 137, pp 265-282, 2007.

[2] Torres A.M., Palacios S.A., Yerkovich N., Palazzini J.M., Battilani P., Leslie J.F., Logrieco A.F., Chulze S.N. Fusarium head blight and mycotoxins in wheat: prevention and control strategies across the food chain. World Mycotoxin Journal, pp 1-24 (in press), 2019.

[3] Aktar W., Sengupta D., Chowdhury A. Impact of pesticides use in agriculture: their benefits and hazards. Interdisciplinary Toxicology, vol. 2/issue 1, pp 1-12, 2009.

[4] Yang D., Wang N., Yan X., Shi J., Zhang M., Wang Z., Yuan H. Microencapsulation of seed-coating tebuconazole and its effects on physiology and biochemistry of maize seedlings. Colloids and Surfaces B, vol. 114, pp 241-246, 2014.

[5] Fernández-Calviño D., Rousk J., Bååth E., Bollmann U. E., Bester K., Brandt K. K. Ecotoxicological assessment of propiconazole using soil bacterial and fungal growth assays. Applied Soil Ecology, vol. 115, pp 27-30, 2017.

[6] Muñoz-Leoz B., Ruiz-Romera E., Antigüedad I., Garbisu C. Tebuconazole application decreases soil microbial biomass and activity. Soil Biology and Biochemistry, vol. 43/issue 10, pp 2176-2183, 2011.

[7] Asrar J., Ding Y., La Monica R. E., Ness L. C. Controlled release of tebuconazole from a polymer matrix microparticle: release kinetics and length of efficacy. Journal of Agricultural and Food Chemistry, vol. 52, pp 4814-4820, 2004.

[8] Wang Y., Li C., Wang Y., Zhang Y., Li X. Compound pesticide controlled release system based on the mixture of poly (butylene succinate) and PLA. Journal of Microencapsulation, vol. 35, pp 494-503, 2018.

[9] Gunning M. A., Geever L. M., Killion J. A., Lyons J. G., Higginbotha C. L. Mechanical and biodegradation performance of short natural fiber polyhydroxybutyrate composites. Polymer Testing, vol. 32, pp 1603-1611, 2013.

[10] Savenkova L., Gercberga Z., Muter O., Nikolaeva V., Dzene A., Tupureina V. PHB-based films as matrices for pesticides. Process Biochemistry, vol. 37, pp 719-722, 2002. 
[11] Angelini S., Cerruti P., Immirzi B., Scarinzi G., Malinconico M. Acid-insoluble lignin and holocellulose from a lignocellulosic biowaste: Bio-fillers in poly(3hydroxybutyrate). European Polymer Journal, vol.76, pp 63-76, 2016.

[12] Volova T. G., Shishatskaya E. I., Zhila N. O., Prudnikova S. V., Boyandin A. N. New Generation Formulations of Agrochemicals: Current Trends and Future Priorities. Apple Academic Press, Canada, 268 p, 2019.

[13] Kah M., Beulke S., Brown C. D. Factors influencing degradation of pesticides in soil. Journal of agricultural and food chemistry, vol. 55/issue 11, pp 4487-4492, 2007.

[14] Baćmaga M., Wyszkowska J., Kucharski J. The effect of the Falcon 460 EC fungicide on soil microbial communities, enzyme activities and plant growth. Ecotoxicology, vol. 25/issue 8, pp 1575-1587, 2016.

[15] Wang C., Wang F., Zhang Q., Liang W. Individual and combined effects of tebuconazole and carbendazim on soil microbial activity. European Journal of Soil Biology, vol. 72, pp 6-13, 2016. 